\title{
IKZF1 genetic variants rs4132601 and rs11978267 and acute lymphoblastic leukemia risk in Tunisian children: a case- control study
}

\author{
Sana Mahjoub ${ }^{1}$, Vera Chayeb ${ }^{1}$, Hedia Zitouni ${ }^{1}$, Rabeb M. Ghali ${ }^{1}$, Haifa Regaieg ${ }^{2}$, Wassim Y. Almawi ${ }^{3,4}$ \\ and Touhami Mahjoub ${ }^{1 *}$ (i)
}

\begin{abstract}
Background: Associations between IKZFI gene variants and Acute Lymphoblastic Leukemia (ALL) was recently reported. We examined whether the common IKZF1 polymorphisms rs4132601 T/G and rs111978267 A/G are associated with ALL among a Tunisian pediatric cohort.

Methods: This case-control study involved 170 patients with ALL and 150 control subjects. SNP genotyping was performed by TaqMan ${ }^{\oplus}$ SNP Genotyping Assay.

Results: The minor allele G of IKZF1 gene polymorphism rs4132601 T/G was significantly higher in ALL cases than in control subjects $(P=0.029)$, with 1.54-fold increased risk of ALL. The association of rs4132601 with ALL was seen under co-dominant $(P=0.009)$, recessive $(P=0.006)$, and additive $(P=0.027)$ genetic models, of which the codominant $(P=0.027)$ and recessive $(P=0.027)$ association remained significant after adjusting for covariates, and False Discovery Rate correction. In contrast, no association was noted for rs 111978267 variant. Two-locus (rs4132601-rs11978267) IKZF1 haplotype analysis demonstrated association of GA ( $P=0.053)$, with increased ALL risk [OR $(95 \% \mathrm{Cl})=1.58(1.00-2.51)]$, which remained significant after controlling for key covariates [aP = 0.046; aOR $(95 \%$ $\mathrm{Cl})=1.61(1.01-2.57)]$
\end{abstract}

Conclusion: We demonstrated the association of IKZF1 polymorphism rs4132601 T/G with increased risk of ALL among Tunisian pediatric cohort, with altered phenotypic changes among ALL patients.

Keywords: Acute lymphoblastic leukemia, Gene polymorphism, IKZF1, rs4132601, rs111978267

\section{Background}

Acute lymphoblastic leukemia (ALL), an aggressive lymphoid cancer, affecting red, white blood cells and platelets. It is reported as the most prevalent hematopoietic malignancy in children worldwide [1,2]. ALL represent about $25 \%$ of cancers that affect people before their twenties; with 2 to 5 years being the peak age. In Tunisia, 25 new children were diagnosed with ALL every year. New treatment strategies have increased the cure rate to $80 \%[3,4]$ and the five-year survival is estimated to $60 \%$ nowadays [2]. ALL is

\footnotetext{
* Correspondence: touhamimahjoub@gmail.com

'Laboratory of Human Genome and Multifactorial Diseases (LR12ES07),

Faculty of Pharmacy of Monastir, University of Monastir, Monastir, Tunisia

Full list of author information is available at the end of the article
}

characterized by infiltration to monoclonal immature cell medullar and extra medullar areas $[5,6]$. ALL is a multifactorial disease that includes the interaction between environmental and genetic factors [7, 8]. Genetic etiology dominates in younger due to lower exposure to environmental factors compared to adults $[8,9]$.

Recent evidence revealed that acquired somatic mutations could contribute to ALL [10]. These mutations increase the proliferation and survival of progenitor cells [10] and impair further cellular differentiation [10]. Although these alterations contribute to the diagnosis and prognosis [10], they are insufficient to understand the physiopathology ALL processes. The introduction of novel diagnostic tools, such as high-resolution karyotyping,

(c) The Author(s). 2019 Open Access This article is distributed under the terms of the Creative Commons Attribution 4.0 International License (http://creativecommons.org/licenses/by/4.0/), which permits unrestricted use, distribution, and reproduction in any medium, provided you give appropriate credit to the original author(s) and the source, provide a link to the Creative Commons license, and indicate if changes were made. The Creative Commons Public Domain Dedication waiver (http://creativecommons.org/publicdomain/zero/1.0/) applies to the data made available in this article, unless otherwise stated. 
CGH array and genome-wide molecular analysis $[6,11]$ may reveal additional somatic mutations not captured by standard cytogenetic analysis. The heritable susceptibility to ALL is proven by the finding of recent candidate-gene and genome-wide association studies (GWAS). Some authors suggested that ALL risk is associated with multiple germline variants [12]; others disprove these hypotheses suggesting that the genetic susceptibility to ALL is mediated by a small number of genes with a strong effect rather than the cumulative effect of small genes [13]. In fact, the first GWAS performed by Trevino and colleagues, identified eighteen germline single nucleotide polymorphisms (SNPs) of 307,944 subjects with allele frequencies are higher in pediatric ALL population that in non-ALL controls $(p<1 \times 10-5)$ [9]. Four loci particular SNPs located in 7p12.2 (IKZF1), 9p12 (CDKN2A/CDKN2B), 10q21.2 (ARID5B) and 14q11.2 (CEBPE) are reported by Sherborne which are associated with ALL risk: RR (1.51.6) and more specifically with the B-cell precursor (BCP) ALL $[14,15]$.

IKAROS one of five members of large Zinc finger proteins (IKAROS, Helios, Aiolos, Eos and Pegasus), and is an important activator in the lymphopoiesis [16]. IKAROS is a potential regulator of lymphocyte commitment and differentiation [17], and immune system development [18]. IKAROS is an important transcription factor expressed in a hematopoietic stem cell that regulates cell proliferation and differentiation during hematopoiesis, particularly in lymphoid cell lineage, and the adaptive immune system $[19,20]$.

IKZF1 gene is located at chromosome 7 encodes IKAROS protein interacting with the deoxynucleotidyl transferase inducing its transcription. It especially targets the zone of dead centromeric chromosomes [21]. It has been reported to have a key role in IKAROS protein dysfunction upon mutations in hematological malignancies, especially in lymphoblastic leukemia [17, 22, 23]. Numerous studies documented the association of gene deletion and ALL [24]. Few studies on African and Asian population investigated the association of single polymorphisms of IKZF1 with infant ALL. Here we explored the association of the IKZF1 gene variants, rs4132601 located on chromosome 7 (position 50,438,098 between rs6964823 and rs6944602, and strongly associated with ALL), and rs11978267 [25], with ALL risk among Tunisian children.

\section{Methods}

\section{Subjects}

From January 2013 to May 2017, we collected 170 children diagnosed with ALL with a mean age of $7.6 \pm 4.5$ years old. The immature blood and bone marrow cells were identified after May-Grunwald- Giemsa (MGG) coloring; the ALL classification was made according to the French-American-British (FAB) recommendations (cooperative group) and cytochemical reactions (myeloperoxidase for AML and esterase for ALL), immunophenotyping was done by Beckman cytoflex. Of these patients, 150 were diagnosed with B-ALL and 20 with TALL. In addition, 150 children with a mean age of $7.9 \pm$ 5.0 years old served as controls, and were recruited from general pediatric service during a routine check-up and were matched to cases according to self-declared ethnic origin. Blood samples were collected from all participants in ethylenediaminetetraacetic acid containing tubes for further genomic DNA extraction. Written informed consent to participate was obtained from the guardians of all of the patients and controls who participated in this study. The data was performed in accordance with the Declaration of Helsinki which was approved by a ethics committee of Farhat Hached university hospital based in Sousse, Tunisia (12/6/2016),

\section{SNP genotyping}

Total genomic DNA was isolated from peripheral blood leukocytes by the salting-out method. Briefly, blood samples were treated with erythrocyte lysis solutions, followed by protease $\mathrm{K}$ digestion. $\mathrm{NaCl}$ was added following centrifugation, and the supernatant was treated with absolute ethanol to precipitate DNA. IKZF1 rs4132601 (170 cases and 150 controls) and rs11978267 (150 cases and 150 controls) genotyping was done using TaqMan $^{\circ}$ SNP genotyping assay. A standard $10 \mu \mathrm{l}$ PCR reaction mix consisted of $1 \mathrm{X}$ TaqMan ${ }^{\circ}$ Genotyping Master Mix (Applied Biosystems), 1X SNP Genotyping Assay Mix and $20 \mathrm{ng}$ of genomic DNA. Genotyping of both rs4132601 (3 subjects) and rs11978267 (17 patients) could not be performed because of poor DNA quality.

\section{Statistical analysis}

Statistical analysis was performed using SPSS 23 (IBM, Armonk, NY). Data were expressed as percentages of total (for categorical variables), or mean $\pm \mathrm{SD}$ (for continuous variables). Student's t-test was used to determine differences in means, and Pearson $\chi^{2}$ test was used to assess inter-group significance. False Discovery Rate (FDR) was performed to control the error type I, using R software version 3.4.3. Power of the study was calculated by Genetic Power Calculator (http://www.bwh.harvard. edu/gpc). Results with a $p$-value $<0.05$ were considered as statistically significant. Genotypes were tested for departures from Hardy-Weinberg equilibrium (HWE) in the control population using Haploview 4.2 (www.broadinstitute.org/haploview). All analyses were conducted under additive genetic model. Pairwise linkage disequilibrium (LD) values were calculated with Haploview 4.2, and haplotype reconstruction was performed by the expectation maximization method. Logistic regression 
analysis was performed in order to determine the odds ratios (OR) and 95\% confidence intervals (CI).

\section{Results}

\section{Study subjects}

The characteristics of ALL patients and control subjects are shown in (Table 1). No significant intergroup differences were recorded for age $(P=0.687)$, or gender $(P=0.533)$. All hematological indices were significantly different between ALL patients and control subjects $(P<0.001)$.

\section{Association studies}

Table 2 summarizes allelic associations and Hardy Weinberg equilibrium between SNPs of the IKZF1 gene and ALL. Genotypes of rs4132601 $(P=0.88)$, and rs11978267 $(P=0.5)$ IKZF1 gene variants were in HWE among control population. Minor $(G)$ allele frequencies (MAF) of rs4132601 was higher in patients and exhibited a significant association with ALL $[P=0.029$; OR $(95 \%$ $\mathrm{CI})=1.54(1.04-2.2)]$, while there was a lack association for rs111978267 A/G with ALL $(P=0.086)$.

According to Table 3, crude results analysis had revealed that the rs4132601 T/G variant was positively associated to ALL risk under the co-dominant model for G/G genotype carriers $[P(=0.006 ;$ OR $(95 \% \mathrm{CI})=4.07$ (1.40-11.79)], under the recessive model of inheritance
$[P=0.0059 ;$ OR $(95 \% \mathrm{CI})=3,80(1.35-10.67)]$, and under the additive model of genetic transmission $[P=0.027$; OR $(95 \% \mathrm{CI})=1,56(1.05-2,34)]$ between ALL patients and control subjects. While significant associations were maintained after adjusting for age and gender covariates, the association under the additive model was lost $[P 00$, 054) after FDR correction. For rs11978267 A/G variant, there were no significant associations between genotypic distributions and ALL susceptibility under any of the models of inheritance (Table 3).

\section{Correlation studies}

We next examined correlations between $I K Z F-1$ variants and ALL-associated hematological and biochemical parameters. As shown in Table 4, for the rs4132601, a negative correlation was denoted for ALL-B blood cell number $(\mathrm{R}=-0.20 ; P=0.03)$ and an inverse positive one was demonstrated for ALL-T immunophenotype $(R=$ $0.20, P=0.03)$. For the rs11978267, nearly significant weak negative correlations were observed for platelet count $(\mathrm{R}=-0.096, P=0.14)$ and $\mathrm{LDH}$ parameters $(\mathrm{R}=$ $-0.286, P=0.18$ ) (Table 4).

\section{Haplotype analysis}

Two-locus [rs4132601 and rs11978267] IKZF-1 haplotype analyses denoted that the majority of the haplotype diversity was captured by 4 haplotypes in controls

Table 1 Characteristics of study participants

\begin{tabular}{|c|c|c|c|}
\hline Parameters & Cases $(N=170)^{c}$ & Controls $(N=150)^{c}$ & $p^{a}$ \\
\hline Mean age (years \pm S.D.) ${ }^{\mathbf{b}}$ & $7.7 \pm 4.5$ & $7.5 \pm 4.5$ & 0.820 \\
\hline Age $\leq 10$ years $^{c}$ & $62 \%$ & $70 \%$ & 1.000 \\
\hline Gender (M:F) ${ }^{\mathbf{d}}$ & $50 \%$ & $44.4 \%$ & 0.797 \\
\hline $\mathrm{WBC}\left(\times 10^{3} / \mu \mathrm{l}\right){ }^{\mathbf{b}}$ & $69.31 \pm 57.7$ & $13.8 \pm 1.9$ & $<0.001$ \\
\hline \multicolumn{4}{|l|}{ WBC category $\left(\times 10^{3} / \mu \mathrm{l}\right)^{\mathbf{c}}$} \\
\hline$<20$ & $60.2 \%$ & $91.4 \%$ & \multirow[t]{3}{*}{$<0.001$} \\
\hline $20-100$ & $17.0 \%$ & $5.6 \%$ & \\
\hline$>100$ & $22.7 \%$ & $0(0.0)$ & \\
\hline $\mathrm{RBC}\left(\times 10^{6} / \mu \mid\right)^{b}$ & $7.8 \pm 2.8$ & $10.9 \pm 2.1$ & $<0.001$ \\
\hline Platelets count $\left(\times 10^{3} / \mu l\right)^{\mathbf{b}}$ & $92,8 \pm 15$ & $356.4 \pm 15.45$ & $<0.001$ \\
\hline Positive family history ${ }^{\mathbf{d}}$ & $9.02 \%$ & N.A & N.A \\
\hline \multicolumn{4}{|l|}{ Immunophenotype } \\
\hline$A L L-B^{d}$ & $88.3 \%$ & N.A & N.A \\
\hline ALL-T- ${ }^{d}$ & $11.7 \%$ & N.A & N.A \\
\hline \multicolumn{4}{|l|}{ Current status } \\
\hline In remission & 119 & N.A & N.A \\
\hline Relapsed & 41 & N.A & N.A \\
\hline Deceased & 10 & N.A & N.A \\
\hline
\end{tabular}

Bold types are indicative of significant association $p>0.05$

N.A. Not applicable

${ }^{\text {a }}$ Student t-test for continuous variables, chi-square analysis for categorical variables; ${ }^{\mathbf{b}}$ Mean \pm SD

${ }^{c}$ Number of subjects (Percentage); ${ }^{\mathbf{d}}$ Percent total 
Table 2 Distribution of IKZF-1 variants alleles in ALL cases and controls

\begin{tabular}{llllllllll}
\hline SNP & Position $^{a}$ & Minor Allele & Cases $^{b}$ & Controls $^{b}$ & HWE & $x^{2}$ & $p^{c}$ & OR (95\% Cl) & Power (\%) \\
\hline rs4132601 T/G & $50,402,906$ & G & $36 \%$ & $26 \%$ & 0.88 & $<0.001$ & 0.029 & $1.54(1.04-2.28)$ & 78.5 \\
rs11978267 A/G & $50,398,606$ & G & $17 \%$ & $11 \%$ & $<0.05$ & 0.283 & 0.086 & $1.57(0.93-2.67)$ & 89.5
\end{tabular}

${ }^{a}$ Location on chromosome based on dbSNP build 125

${ }^{b}$ Minor allele (frequency)

cAdjusted $p$ value, adjusted for age and gender

HWE Hardy-Weinberg Equilibrium

SNP Single Nucleotide Polymorphism

rs4132601 is significant associated with ALL $(P<0.05)$

(96.1\%) and cases (100\%), namely TA, GA, GG, TG. Taking the common TA haplotype as reference $(\mathrm{OR}=1.00)$, univariate and multivariate analyses demonstrated an association of GA $[P=0.053$; OR $(95 \% \mathrm{CI})=1.58(1.00-2.51)]$ haplotypes with ALL (Table 5). This remained significant after controlling for age and gender $[a P=0.046$; $\mathrm{aOR}$ $(95 \% \mathrm{CI})=1.61(1.01-2.57)]$.

\section{Discussion}

Genetic studies contributed to the understanding of the physiopathological mechanisms of malignant diseases such as leukemia. In fact, the genetic alterations are a major etiology of children leukemia which helps to explain the potential risk for ALL. Xu and colleagues hypothesized that the genetic susceptibility to ALL is mediated by a small number of genes with strong effect rather than the cumulative effect of small genes [13].

Genome association studies have identified the IKZF-1 gene polymorphism frequency through the deletion and single mutations in the children with ALL as compared to the controls [24-26].

We examined the association between rs4132601 and ALL risk in 170 Tunisian pediatric patients. Our results (Table 3) confirm those of Papaemmanuil and colleagues, who reported the association of the IKZF1 gene polymorphism rs4132601, localized in $3^{\prime}$ region of the IKAROS family zinc finger 1 (IKZF1) gene with a pediatric ALL risk [25]. It is in LD with rs6964823 and rs6944602 that form a block between 3' UTR and intron 7 of IKZF1 [25]. However, previous studies that have examined the association between IKZF1 rs4132601 polymorphism and acute lymphoblastic leukemia (ALL) risk reached controversial results. Li et al. analyzed 15 casecontrol studies with 8333 cases and 36,036 controls in a meta-analysis [26]. The results suggested that rs4132601 was associated with an increased ALL risk. Significant associations were found among Caucasians and Hispanics [27, 28], but not among Asians [29]. On the other hand, when data are stratified by disease type, rs4132601

Table 3 Genotypic distributions of the rs4132601 T/G and rs11978267 A/G variants between cases and controls according to different models of genetic transmission

\begin{tabular}{|c|c|c|c|c|c|c|c|c|c|}
\hline$\overline{S N P}$ & Model & Genotype & Cases (\%) & Controls (\%) & & OR $(95 \% \mathrm{Cl})$ & $a P^{a}$ & $P$ corr $^{b}$ & $\mathrm{aOR}(95 \% \mathrm{Cl})^{a}$ \\
\hline \multirow[t]{7}{*}{ rs4132601 } & \multirow[t]{3}{*}{ Codominant } & $\mathrm{T} / \mathrm{T}$ & $43 \%$ & $51 \%$ & - & 1.00 (Reference) & - & - & 1.00 (Reference) \\
\hline & & $T / G$ & $43 \%$ & $45 \%$ & 0.60 & $1.15(0.67-1.96)$ & 0,58 & 0.696 & $1.16(0.68-1.99)$ \\
\hline & & $\mathrm{G} / \mathrm{G}$ & $14 \%$ & $4 \%$ & 0.006 & $4.07(1.40-11.79)$ & 0,009 & 0.027 & $4.21(1.42-12.44)$ \\
\hline & Dominant & $\Pi$ vs. $T G+G / G$ & 43.2 vs. $56.8 \%$ & 51.3 vs. $48.7 \%$ & 0.19 & $1.40(0.84-2.34)$ & 0.19 & 0.285 & $1.41(0.84-2.36)$ \\
\hline & Recessive & $\Pi+\mathrm{TG}$ vs. G/G & $86.4 \%$ vs. $13.6 \%$ & $95.8)$ vs. $4.2 \%$ & 0.0059 & $3.80(1.35-10.67)$ & 0.006 & 0.027 & $3.91(1.37-11.19)$ \\
\hline & Over-dominant & $T / T+G / G$ vs. T/G & 56.8 vs. $43.2 \%$ & $55.5 v s .44 .5 \%$ & 0.79 & $0.93(0.56-1.56)$ & 0.83 & 0.830 & $0.95(0.56-1.58)$ \\
\hline & Additive & - & - & - & 0.027 & $1.56(1.05-2.34)$ & 0.027 & 0.054 & $1.58(1.05-2.37)$ \\
\hline \multirow[t]{7}{*}{ rs11978267 } & \multirow[t]{3}{*}{ Codominant } & $\mathrm{A} / \mathrm{A}$ & $75 \%$ & $81 \%$ & - & 1.00 (Reference) & - & - & 1.00 (Reference) \\
\hline & & $\mathrm{A} / \mathrm{G}$ & $16 \%$ & $14 \%$ & 0.56 & $1.23(0.59-2.55)$ & 0,49 & 0.588 & $1.29(0,61-2.70)$ \\
\hline & & $\mathrm{G} / \mathrm{G}$ & $9 \%$ & $5 \%$ & 0.15 & $2.20(0.75-6.43)$ & 0,16 & 0.30 & $2.16(0.73-6.37)$ \\
\hline & Dominant & $\mathrm{A} / \mathrm{A}$ vs. $\mathrm{A} / \mathrm{G}+\mathrm{G} / \mathrm{G}$ & 74.8 vs. $25.2 \%$ & $81.5 \%$ vs. $18.5 \%$ & 0.23 & $1.47(0.78-2.75)$ & 0.2 & 0.30 & $1.51(0.80-2.85)$ \\
\hline & Recessive & $\mathrm{A} / \mathrm{A}+\mathrm{A} / \mathrm{G}$ vs. $\mathrm{G} / \mathrm{G}$ & $90.9 \%$ vs.9.1\% & 95.6 vs. $4.4 \%$ & 0.16 & $2.13(0.73-6.18)$ & 0.18 & 0.30 & $2.08(0.71-6.10)$ \\
\hline & Over-dominant & A/A-G/G vs. A/G & $83.8 \%$ vs. $16.2 \%$ & 85.9 vs. $14.1 \%$ & 0.68 & $1.16(0.56-2.39)$ & 0.59 & 0.59 & $1.22(0.59-2.55)$ \\
\hline & Additive & - & - & - & 0.15 & $1.40(0.89-2.19)$ & 0.14 & 0.30 & $1.41(0.89-2.22)$ \\
\hline
\end{tabular}

${ }^{a} a P$, aOR: $p$-value and odds ratio are adjusted by age and gender

${ }^{b} P$ corr.: FDR corrected $p$-value

SNP Single Nucleotide Polymorphism

Bold faced values are indicative of significant association $(p<0.05)$ 
Table 4 Pearson correlations of IKZFI studied variants

\begin{tabular}{llllll}
\hline Factor & \multicolumn{2}{l}{ rs4132601 } & & \multicolumn{2}{r}{ rs11978267 } \\
\cline { 2 - 3 } & $P$ & $\mathrm{R}$ & & $P$ & $\mathrm{R}$ \\
\hline Gender & 0.26 & 0.10 & & 0.52 & -0.06 \\
Immunophenotype & & & & \\
$\quad$ ALL-B & $\mathbf{0 . 0 3}$ & $\mathbf{0 . 2 0}$ & & 0.20 & 0.12 \\
$\quad$ ALL-T & $\mathbf{0 . 0 3}$ & $-\mathbf{0 . 2 0}$ & & 0.20 & -0.12 \\
WBC & 0.40 & 0.054 & & 0.20 & -0.04 \\
Platelets count & 0.53 & -0.04 & $\mathbf{0 . 1 4}$ & $-\mathbf{0 . 0 9}$ \\
LDH & 0.25 & -0.21 & $\mathbf{0 . 1 8}$ & $-\mathbf{0 . 2 8}$ \\
Current status & 0.89 & -0.01 & 0.30 & -0.11 \\
\hline
\end{tabular}

$P$ : $p$-value

R: Pearson correlation coefficient

Bold -faced values are indicative of a significant association

WBC White Blood Cells

LDH Lactate dehydrogenase

increased significantly risks in B-cell ALL and B hyperdiploid ALL, but not among T-cell ALL and AML subgroups [26-30]. Our results showed that the G allele of rs4132601 is more frequent in patients than the control, which increased the ALL risk in Tunisian children. However, Dai and colleagues suggested in their metaanalysis that Europeans but not Asian G allele carriers children had a markedly increased risk of ALL [30, 31].

Several studies have been conducted to examine the possible interaction between IKZF1 G allele of rs4132601 and environmental ALL risk factors. Rudant and colleagues reported a negative correlation of $I K Z F 1$ allele risk with maternal use of home insecticides during pregnancy and positive interactions with early immune modulation, breastfeeding, and history of repeated early common infections, but there was no risk with paternal preconception smoking [32]. Rudant and Linabery noted that some selected demographic factors such as birth weight and maternal age don't change the risk of some SNPs of ARID5B and IKZF1 [32, 33]. Also, Linabery and Evans in their independent studies showed an evident interaction between rs4132601 risk and paternal preconception smoking or maternal use of foli IKZF1c acid $[33,34]$.

The rs4132601 is a substitution polymorphism $(\mathrm{T}>\mathrm{G})$ located in 3'UTR to the IKAROS Family zinc finger 1
(IKZF1) gene (located on 7p12.2). IKAROS proteins are major regulators of lymphocyte maturation and CD4, CD8 T-cell lineage differentiation [35]. The animal model revealed that mice without IKAROS protein develop aggressive lymphoblastic leukemia [36, 37]. However, the role of the rs4132601 in the leukemogenesis is unclear; Górniak and colleagues hypothesized that the $\mathrm{G}$ allele decreases the stability and level of the mRNA expression; which delays progression through B-cell maturation and increases the risk of ALL [25, 38]. Lautner-Csorba and colleagues reported that the rs4132601 strongly increases the probability (0.97) of ALL and showed that the lower expression associated with the rs4132601 might contribute to the increased vulnerability to the disease [39]. Our results had disapproved of this hypothesis. The Pearson test did not demonstrate any correlation between rs4132601 and current state (death, relapse) (Table 5).

The rs11197867 IKZF1 gene variant, the second investigated polymorphism, is an intronic polymorphism located at the position 50,433,798 of chromosome 7. Our data showed the lack of association of rs11197867with ALL, irrespective of the genetic model used. To our knowledge, few studies have replicated this polymorphism. Dai and colleagues in their meta-analysis of 20 studies with 4960 patients and 28,034 controls reported that the rs11978267 polymorphism in the IKZF1 gene increased significantly AL risk [31], especially among Europeans $[28,33,40]$ but not among African and mixed populations [13]. When stratified by types of ALL, a significant correlation was found in the BCP-ALL subgroup in the allelic and ALL genetic models. Moreover, ethnicity appears to change ALL risk. In fact, Europeans with a $G$ allele had a markedly increased risk of ALL, which was not observed among Asians [30].

Mixed Lineage Leukemia (MLL) gene rearrangements assigns a poor prognostic [41] in both ALL and AML infant cases. In fact, MLL status markedly influences the five-year survival rates for infant ALL. It's reported that $80 \%$ of ALL infants with negative MLL rearrangement live up to 5 years or more. The risk death increase with ALL/MLL+. However, this influence is less pronounced in infant AML. Further, ALL/MLL+ infants are usually diagnosed as early as the age of 6 months while those

Table 5 IKZF-1 haplotypes distributions in cases and controls

\begin{tabular}{lllllll}
\hline Haplotype $^{a}$ & Cases & Controls & $P$ & $\mathrm{OR}^{b}(95 \% \mathrm{Cl})$ & $a P$ & $\mathrm{aOR}{ }^{b}(95 \% \mathrm{Cl})$ \\
\hline T A & $0.571^{c}$ & 0.690 & - & 1.00 (Reference) & - & $1.00($ Reference) \\
G A & 0.256 & 0.193 & $\mathbf{0 . 0 5 3}$ & $\mathbf{1 . 5 8}(\mathbf{1 . 0 0 - 2 . 5 1 )}$ & $\mathbf{0 . 0 4 6}$ & $\mathbf{1 . 6 1}(\mathbf{1 . 0 1 - 2 . 5 7 )}$ \\
GG & 0.1 & 0.068 & $\mathbf{0 . 0 9 5}$ & $\mathbf{1 . 7 7}(\mathbf{0 . 9 1 - 3 . 4 6 )}$ & $\mathbf{0 . 0 8 9}$ & $\mathbf{1 . 8}(\mathbf{0 . 9 2 - 3 . 5 5 )}$ \\
TG & 0.071 & 0.047 & 0.33 & $1.43(0.69-2.96)$ & 0.37 & $1.4(0.68-2.89)$ \\
\hline
\end{tabular}

${ }^{a}$ Haplotype containing rs4132601 T/G and rs11978267 A/G

b $a P$; $a O R$ adjusted odds ratio; covariates that were controlled for were age and gender

c Haplotype frequency determined by the maximum likelihood method

Bold-faced values are indicating a significant association 
with ALL/MLL- are often depicted in older infants [41]. Burkhardt asserted that the combined cytogenetic MLL with a homozygote variant IKZF1 allele (rs1197867) increases infant leukemia risk. The risk is similarly increased among young patients with AML/MLL+ and AML/MLL- but only among young patients with ALL/ MLL+ [42].

Papaemmanuil and colleagues showed a functional effect for rs4132601, which is in complete linkage disequilibrium with rs11978267, since each additional copy of the variant allele resulted in greater attenuation of IKZF1 mRNA expression, and consequently induced leukemia [25].

The IKZF1 gene is polymorphic. Churchman and al. identified 28 germline IKZF1 variants in children with ALL, mostly in B-ALL [43]. The Iranian (Persian) study including four polymorphisms of the IKZF1 gene rs4132601 T > G, rs11980379 $\mathrm{T}>\mathrm{C}$, and rs10272724 $\mathrm{T}>$ C, rs11978267 A > G showed that the first three are associated with risk ALL under the dominant model and that rs11978267 A / G is not associated [44]. Moreover, Oris et al. reported that the four polymorphisms studied rs696823, rs11978267, rs4132601 and rs6944602 are risk factors for ALL [28]. Yemeni study has noted the association between rs10235796 and rs6964969 variants and ALL, with a borderline association denoted for IKZFI rs4132601 T/G variant and a lack of association between rs11978267, rs7789635 and ALL [45].

\section{Conclusion}

Our study confirms that the IKZF1 rs4132601 T/G variant is the risk factor of ALL in the Tunisian pediatric cohort but not the rs11978267 A/G variant. Our results contrivers some other, this might be partly attributed to small sample sizes and ethnic differences across studies. In the other hand, the genetic alterations of IKZF1 could contribute to the prognosis so that the rs4132601 is associated with ALL immunophenotypes. Our study has several strengths, notably it is one of the few NorthAfrican studies replicating such polymorphisms with a considerable statistical power. Further studies with larger sample sizes and more polymorphisms are needed to confirm the role of the IKZF1 gene in the pathophysiology of ALL.

\footnotetext{
Abbreviations

ALL: Acute Lymphoblastic Leukemia; AML: Acute Myeloid leukemia; ARID5B: AT-Rich Interaction Domain 5B; B-ALL: B-cell Acute Lymphoblastic Leukaemia; CD: Cluster of Differenciation; CDKN2A: Cyclin-Dependent Kinase Inhibitor 2A; CDKN2B: Cyclin-Dependent Kinase Inhibitor 2B; CEBPE: CCAAT/ Enhancer Binding Protein; FDR: False Discovery Rate; GWAS: Genome-Wide Association Studies; HWE: Hardy-Weinberg equilibrium; IKZF1: IKAROS Family Zinc Finger 1; LD: Linkage disequilibrium; MLL: Mixed Lineage Leukemia; WHO: World Health Organization
}

\section{Acknowledgments}

We wish to express our gratitude to all the participants in the study, particularly the young patients.

\section{Authors' contributions}

SM Processed samples, genotyping assays, statistical analysis, drafting of the manuscript. sanamahjoub0903@gmail.com. VC Edited the initial draft of the manuscript, performed statistical analysis; vchaieb@yahoo.fr. HZ Performed statistical analysis. hediaztn@gmail.com. RG Performed genotyping assays. elghali.rabeb@gmail.com. HR Selected patients. regaieghaifa@yahoo.fr.WYA Editing of the manuscript for content and style. wassim.almawi@outlook. com. TM Project leader. touhamimahjoub@gmail.com. All authors read and approved the final manuscript.

\section{Funding}

This work was supported by the Ministry of Higher Education and Scientific Research of Tunisia. The funding body played no role in the design of the study and collection, analysis, and interpretation of data and in writing the manuscript.

\section{Availability of data and materials}

The datasets used and/or analysed during the current study available from the corresponding author on reasonable request. You could contact $\mathrm{Pr}$ Touhami Mahjoub: email: touhamimahjoub@gmail.com

\section{Ethics approval and consent to participate}

Written informed consent to participate was obtained from the guardians of all of the patients and controls who participated in this study. The study was conducted in accordance with the Declaration of Helsinki, which was approved by a ethics committee of Farhat Hached University Hospital in Sousse, Tunisia (granted on June 12, 2016)

Consent for publication

Not applicable.

\section{Competing interests}

The authors declare that they have no competing interests.

\section{Author details}

'Laboratory of Human Genome and Multifactorial Diseases (LR12ES07), Faculty of Pharmacy of Monastir, University of Monastir, Monastir, Tunisia. ${ }^{2}$ Hematology Department ; Faculty of Medicine Ibn Jazzar, University of Sousse, Sousse, Tunisia. ${ }^{3}$ Faculty of Sciences, El-Manar University, Tunis, Tunisia. ${ }^{4}$ School of Medicine, Nazarbayev University, Nur-Sultan, Astana, Kazakhstan.

Received: 26 April 2019 Accepted: 30 September 2019

Published online: 11 October 2019

\section{References}

1. Lautner-Csorba O, Gézsi A, Erdélyi DJ, Hullám G, Antal P, Semsei ÁF, et al. Roles of genetic polymorphisms in the folate pathway in childhoodacute lymphoblastic leukemia evaluated by Bayesian relevance and effect size analysis. PLoS One. 2013;8:e69843.

2. Pui CH, Evans WE. Treatment of acute lymphoblastic leukemia. N Engl J Med. 2006:354:166-78

3. Yang JJ, Cheng C, Devidas M, Cao X, Campana D, Yang W et al. Genomewide association study identifies germline polymorphisms associated with relapse of childhood acute lymphoblastic leukemia. Blood. 2012;120:4197S4204.

4. Tallen G, Ratei R, Mann G, Kaspers G, NiggliF KA, et al. Long-term outcome in children with relapsed acute lymphoblastic leukemia after time-point and site-of-relapse stratification and intensified short-course multidrug chemotherapy: results of trial ALL-REZ BFM 90. J Clin Oncol. 2010;28:2339-47.

5. Mittelman F. The Third International Workshop on Chromosomes in Leukemia. Lund, Sweden, July 21-25, 1980. Introduction. Cancer Genet Cytogenet. 1981:4:96-8.

6. Mullighan CG, Su X, Zhang J, Radtke I, Phillips LA, Miller CB, et al. Children's oncology group. Deletion of IKZF1 and prognosis in acute lymphoblastic leukemia. N Engl J Med. 2009;360:470-80.

7. Peyrouze P, Guihard S, Grardel N, Berthon C, Pottier N, Pigneux A, et al. Genetic polymorphisms in ARID5B, CEBPE, IKZF1 and CDKN2A in relation with risk of acute lymphoblastic leukaemia in adults: a Group for Research 
on Adult Acute Lymphoblastic Leukaemia (GRAALL) study. Br J Haematol. 2012;159:599-602.

8. Lausten-Thomsen U, Madsen HO, Vestergaard TR, Hjalgrim H, Nersting J, Schmiegelow K, et al. Prevalence of t (12;21)[ETV6-RUNX1]-positive cells in healthy neonates. Blood. 2011;117:186-9.

9. Treviño LR, Yang W, French D, Hunger SP, Carroll WL, Devidas M, et al. Germline genomic variants associated with childhood acute lymphoblastic leukemia. Nat Genet. 2009:41:1001-5.

10. Mrozek K, Harper DP, Aplan PD. Cytogenetics and molecular genetics of acute lymphoblastic leukemia. Hematol Oncol Clin. 2009;23:991-1010.

11. Rinke J, Schäfer V, Schmidt M, Ziermann J, Kohlmann A, Hochhaus A, et al. Genotyping of 25 leukemia-associated genes in a single work flow by nextgeneration sequencing technology with low amounts of input template DNA. Clin Chem. 2013;59:1238-50.

12. Offenmüller S, Ravindranath Y, Goyette G, Kanakapalli D, Miller KS, Brecht IB, et al. Focused screening of a panel of cancer-related genetic polymorphisms reveals new susceptibility loci for pediatric acute lymphoblastic leukemia. Pediatric Blood Cancer. 2014;8:1411-5.

13. Xu H, Yang W, Perez-Andreu V, Devidas M, Fan Y, Cheng C, et al. Novel susceptibility variants at 10p12.31-12.2 for childhood acute lymphoblastic leukemia in ethnically diverse populations. J Natl Cancer Inst. 2013;10:733-42.

14. Prasad RB, Hosking FJ, Vijayakrishnan J, Papaemmanuil E, Koehler R, Greaves M. Verification of the susceptibility loci on 7p12.2, 10q21.2, and 14q11.2 in precursor B-cell acute lymphoblastic leukemia of childhood. Blood. 2010;9: $1765-7$.

15. Sherborne AL, Hosking FJ, Prasad RB, Kumar R, Koehler R, Vijayakrishnan J. Variation in CDKN2A at 9p21.3 influences childhood acute lymphoblastic leukemia risk. Nat Genet. 2010;42:492-4.

16. Fan Y, Lu D. The Ikaros family of zinc-finger proteins. Acta Pharm Sin B. 2016;6:513-21.

17. Clevers HC, Oosterwegel MA, Georgopoulos K. Transcription factors in early T-cell development. Immunol Today. 1993;14:591-6.

18. Cortes M, Wong E, Koipally J, Georgopoulos K. Control of lymphocyte development by the Ikaros gene family. Curr Opin Immunol. 1999;11: $167-71$

19. Winandy S, Wu L, Wang JH, Georgopoulos K. Pre-T cell receptor (TCR) and TCR-controlled checkpoints in T cell differentiation are set by lkaros. J Exp Med. 1999;190:1039-48.

20. Kano G, Morimoto A, Takanashi M, Hibi S, Sugimoto T, Inaba T, et al. Ikaros dominant negative isoform (IK6) induces IL-3-independent survival of murine pro-B lymphocytes by activating JAK-STAT and up-regulating BCl-xl levels. Leuk Lymphoma. 2008;49:965-73.

21. Cobb BS, Morales-Alcelay S, Kleiger G, Brown KE, Fisher AG, Smale ST. Targeting of Ikaros to pericentromeric heterochromatin by direct DNA binding. Genes Dev. 2000;14:2146-60.

22. Molnár A, Georgopoulos K. The Ikaros Gene Encodes a Family of Functionally Diverse Zinc Finger DNA-Binding Proteins. Mol Cell Biol. 1994; 14:8292-303.

23. John $L B$, Ward $A C$. The Ikaros gene family: transcriptional regulators of hematopoiesis and immunity. Mol Immunol. 2011;48:1272-8.

24. Mullighan CG, Su X, Zhang J, Radtke I, Phillips LAA, Miller CB, et al. Deletion of IKZF1 and prognosis in acute lymphoblastic leukemia. N Engl J Med. 2009;360:470-80

25. Papaemmanuil E, Hosking FJ, Vijayakrishnan J, Price A, Olver B, Sheridan E, et al. Loci on 7p12.2, 10q21.2 and 14q11.2 are associated with risk of childhood acute lymphoblastic leukemia. Nat Genet. 2009;41:1006-10.

26. Li S, Ren L, Fan L, Wang G. IKZF1 rs4132601 polymorphism and acute lymphoblastic leukemia susceptibility: a meta-analysis. Leuk Lymphoma. 2015;56:978-82.

27. Vijayakrishnan J, Sherborne AL, Sawangpanich R, Hongeng S, Houlston RS Pakakasama S. Variation at 7p12.2 and 10q21.2 influences childhood acute lymphoblastic leukemia risk in the Thai population and may contribute to racial differences in leukemia incidence. Leuk Lymphoma. 2010;51:1870-4.

28. Orsi L, Rudant J, Bonaventure A, Goujon-Bellec S, Corda E, Evans TJ, et al. Genetic polymorphisms and childhood acute lymphoblastic leukemia: GWAS of the ESCALE study (SFCE). Leukemia. 2012;26:2561-4.

29. Lin CY, Li MJ, Chang JG, Liu SC, Weng T, Wu KH et al. High-resolution melting analyses for genetic variants in ARID5B and IKZF1 with childhood acute lymphoblastic leukemia susceptibility loci in Taiwan. Blood Cells Mol Dis. 52(2-3):140-45.
30. Dai YE, Tang L, Healy J, Sinnett D. Contribution of polymorphisms in IKZF1 gene to childhood acute leukemia: a meta-analysis of 33 case-control studies. PLoS One. 2014;9:e113748.

31. Kreile M, Piekuse L, Rots D, Dobele Z, Kovalova Z, Lace B. Analysis of possible genetic risk factors contributing to development of childhood acute lymphoblastic leukaemia in the Latvian population. Arch Med Sci. 2016;12:479-85.

32. Rudant J, Orsi L, Bonaventure A, Goujon-Bellec S, Baruchel A, Petit A, et al. ARID5B, IKZF1 and Non-Genetic Factors in the Etiology of Childhood Acute Lymphoblastic Leukemia: The ESCALE Study. PLoS One. 2015;10:e0121348.

33. Linabery AM, Blommer CN, Spector LG, Davies SM, Robison LL, Ross JA. ARID5B and IKZF1 variants, selected demographic factors, and childhood acute lymphoblastic leukemia: A report from the Children's Oncology Group. Leuk Res. 2013;37:936-42.

34. Evans TJ, Milne E, Anderson D, de Klerk NH, Jamieson SE, Talseth-Palmer BA, et al. Confirmation of childhood Acute Lymphoblastic Leukemia variants, ARID5B and IKZF1, and interaction with parental environmental exposures. PLoS One. 2014;9:e110255.

35. Harker N, Naito T, Cortes M, et al. The CD8 alpha gene locus is regulated by the Ikaros family of proteins. Mol Cell. 2002;10:1403-15.

36. Georgopoulos K, Bigby M, Wang JH, Molnar A, Wu P, Winandy S, Sharpe A. The Ikaros gene is required for the development of all lymphoid lineages. Cell. 1994;79:143-56

37. Klug CA, Morrison SJ, Masek M, Hahm K, Smale ST, Weissman IL. Hematopoietic stem cells and lymphoid progenitors express different Ikaros isoforms, and Ikarosis localized to heterochromatin in immature lymphocytes. Proc Natl Acad Sci U S A. 1998;95:657-62.

38. Górniak P, Pastorczak A, Zalewska-Szewczyk B, Lejman M, Trelińska J, Chmielewska M, et al. Polish Pediatric Leukemia/Lymphoma Study Group. Polymorphism in IKZF1 gene affects age at onset of childhood acute lymphoblastic leukemia. Leuk Lymphoma. 2014;55:2174-8.

39. Lautner-Csorba O, Gézsi A, Semsei AF, Antal P, Erdélyi DJ, Schermann G, et al. Candidate gene association study in pediatric acute lymphoblastic leukemia evaluated by Bayesian network based Bayesian multilevel analysis of relevance. BMC Med Genomics. 2012;5:42.

40. Behm FG, Raimondi SC, Frestedt JL, Liu Q, Crist WM, Downing JR, et al. Rearrangement of the MLL gene confers a poor prognosis in childhood acute lymphoblastic leukemia, regardless of presenting age. Blood. 1996;87: 2870-7.

41. Nagayama J, Tomizawa D, Koh K, Nagatoshi Y, Hotta N, Kishimoto T, et al. Infants with acute lymphoblastic leukemia and a germline MLL gene are highly curable with use of chemotherapy alone: results from the Japan infant leukemia study group. Blood. 2006;107:4663-5.

42. Borkhardt A, Wuchter C, Viehmann S, Pils S, Teigler-Schlegel A, Stanulla M, et al. Infant ALL was combined to combined cytogenetic, immunophenotypical and molecular analysis of 77 Leukemia cases. Leukemia. 2002;16:1685-90.

43. Churchman MQ, Ranran Z, Geertruy K, Wenijian Y, Hui Z, Tobia L, et al. Germline Genetic Variation in IKZFI and Predisposition to Childhood Acute Lymphoblastic Leukemia. Blood. 2016;128:LBA-2.

44. Bahari G, Hashemi M, Naderi M, Taheri M. IKZF1 gene polymorphisms increased the risk of childhood acute lymphoblastic leukemia in an Iranian population. Tumour Biol. 2016;37(7):9579-86.

45. Al-Absi B, Fazril M, Razif M, Muniandy S. Contributions of IKZF1, DDC, CDKN2A, CEBPE, and LMO1 gene polymorphisms to acute lymphoblastic leukemia in a Yemeni population. Genet Test Mol Biomarkers. 2017;21(10): 592-99.

\section{Publisher's Note}

Springer Nature remains neutral with regard to jurisdictional claims in published maps and institutional affiliations. 